would have to be very greatly extended. It was, no doubt, improper of Mr. Barnaby to make the use he did of the Committee's words, and Mr. Reed took no pains to credit the Committee with anything beyond what was written; but Dr. Woolley is, we think, a litile forgetful. of the fact that what $\mathrm{Mr}$. Reed wrote, and what we have since written, has had to be said in presence of the circumstance that in a matter of the gravest public importance a free use of the Committee's words has been made by a high authority for the purpose of claiming for the Inflexible public confidence in her stability on the ground of range only. It is satisfactory to learn, however, on the undoubted authority of Dr. Woolley that the Committee, whatever its language, not only inetnded to give no countenance to the doctrine that the Inflexible would be proved safe if only she were shown to possess sufficient range of stability, but individually and collectively would consider such a doctrine as altogether absurd.

On the second portion of Dr. Woolley's letter, we entirely concur with him. We have read over again both the evidence and the reports of the Committee of Designs, and we cannot find the smallest justification for the assumption that, right or wrong, the Committee on Designs is responsible for this ship's design. The case to the contrary is absolutely clear and unquestionable. Mr. Reed placed before the Committee the outline ideas of a ship of this description, but making it a sine quâ non-let it in justice to him be said-that the ship should not depend "in the least degree" upon the ends, and that the stability of the citadel should be so ample as "to make it a matter of perfect indifference how much the ends might be knocked about by shot and shell." He spoke of the ends as being filled with water, and thus converted into a sort of tanks, and it most naturally occurred to the committee to suggest whetlier cork or some metallic cellular material, might not with advantage be employed to take in some degree the place of water, a proposal which Mr. Reed thought well worth consideration and trial. Beyond this the Committee did not go in their reporf, as the quotations cited by Dr. Woolley clearly show on the contrary, by recommending the course of experimental investigation which they advised they plainly showed that, in their opinion, sufficient grounds for depending upon cork, \&c., for stability did not exist, and could not be shown to exist except by large and well-considered experiments. Mr. Barnaby roundly asserts that the Committee "did not agree with Mr. Reed's view as to the necessary dependence of the ship upon her armoured citadel for her floating power ; "but the ex'racts from the Committee's Report which he adduces in support of the statement by no means bear it out. The Committee, for some reason or other, advert to Mr. Reed's plan without mentioning his name, but, while nowhere implying any dissent from his main principle, they plainly enough indicate that armour should be employed to sufficiently protect buoyancy and stability, unless "other means than armour-plating" could be found and proved effectual.

We shall defer to Dr. Woolley's very proper wish to restrict his remarks to the two points above considered, and shall in no way seek to connect them with the general question upon which he has been appointed a judge. We may be permitted to observe, however, that whatever the result may be, it is a satisfaction to us to find that the Committee consists of gentlemen who are in large part not merely masters of the science of the stability of floating structures, and raised high by their individual repute above the suspicion of partisanship, but who also, by serving on the Committee of Designs of $187 \mathrm{I}$, acquired very special fitness for promptly considering the Infexible case. They will knov how to go directly to the questions at issue, and after ascertaining what stability the ship actually possesses withont aid from cork, or canvas, or other devices, and what she possesses with such sid, they will be able to declare with scientific confidence and precision whether it is or is not sufficient, for they are themselves the authors of the very standards by which that issue must be decided. Nor will they forget that whatever demands for stability existed in $187 \mathrm{r}$, still greater demands now exist when we have the First Lord of the Admiralty, in his place in Parliament, claiming for this very ship the ability to float and fight even af er three successive blows from Whitehead torpedoes. If the result should be a disproof of our views of the subject, we know that that disproof will be based upon scientific grounds that will commend themselves to impartial minds. If the result should te to require that additional stability shall be provided in such ships, a great public good will bave been accomplished. We need not say which result we anticipate--En. NATURE.]

\section{The Manufacture of Leading Articles}

THERE is a good old story told of a country editor who once met a pressing demand for copy in a singularly ingenious manner. At the moment of going to press, it was found to the consterna. tion of the printer that a whole column was lacking. What was to be done? The whole staff was in confusion at the unexpected discovery; the editor alone preserved his wonted coolness. Sending for a copy of the Times, be clipped therefrom one of the leaders and ordered it at once to be set up in type, prefaced by the words "What does the Times mean by this?"

This story recurred to me with some force on reading on the front page of Land and Water last week, an article on Soldiers' Food in War; for the original, bearing my signature, appeared on the front page of NATURE (vol. xvi. p. 157). In this case, however, my other self seems to have had more time on his hands than the country editor, since the article in question has been paraphrased in parts, still with such care as not to destroy the identity.

July 24

H. BADEN PRITCHARD

\section{The Fish-sheltering Medusa}

Probably the suecies of fish to which Mr. Lawless refers as seeking shelter under the swimming-disc of Aurelia aurita (NATURE, vol. xvi. p. 227) is Morlangus carbonarius (Cuv.), popularly called boat-fish. At least I have seen the fry of this species behaving as Mr. Lawless describes.

The observation stated in the following words appears to me one of great interest :- "Occasionally the Medusa turned in its pulsations, so as to bring the umbrella uridermost, when the fish would shoot hastily out, but the Medusa had no sooner righted itself, than the fish returned." Now, if this occasional turning on the part of the Medusa was not merely accidental, but, as Mr. Lawless implies, a refiex act performed with the view of escaping from the irritation occasioned by the fish, the fact would show that the marginal ganglia of Aurelia aurita are so far co-ordinated in their action as to enable the animal to steer itself in any required direction. For my own part, I have not as yet been able to satisfy myself that such ganglionic co-ordina. tion occurs in any species of covered-eyed Medusa; so it would be well worth while if Mr. Lawless could repeat his observation a sufficient number of times to exclude the supposition of the somersaults being merely fortuitous.

I may take this opportunity of saying that the cut which illustrates the abstract of my lecture on p. 232 of the same issue of NATURE as contains Mr. Lawless's letter, is intended to represent the species of Medusa to which he refers, viz., Aurelia aurita. The cut is about $\frac{1}{8}$ natural size.

George J. Romanes

\section{Phyllotaxis}

I Have noticed in the laurel and the Spanish chestnut species, in which the leaves have normally a distichous arrangement, that when a vigorous shoot takes a vertical direction-for example, after the stock has been cut down near the ground---the leafage of such a shoot is often quincuncial. The phenomenon suggests three possible interpretations. Is this to be regarded as a fixed adaptive habit, the spiral phyllotaxis being the fittest for the upright, the two-ranked for the more numerous lateral twigs? Or are the exceptional instances endeavours after greater economy of space in the packing of the buds? Or, finally, ought we to discern in the peculiarities of the more vigorous shoots a reversion towards some ancestral condition? W. E. HART

Drumaweir, Greencastle, July 20

\section{Printing and Calico-Printing}

As ail that I am ever personally concerned to know is the truth of a matter, I am glad to siand corrected by the writer of the article on Calico-Printing in the "Encyclopædia Britannica." The claim I made, however, for the author of the "Natural History of Enthusiasm" was not my own invention; and it would be of interest, I think, to the many who must still, even in our day, revere his memory, to know more fully and accurately what it was that engrossed so many years of his valuable life, and what, if any, have been the practical results.

Bregner, Bournemouth, July 23 